\title{
Outcome of Metastatic GIST in the Era before Tyrosine Kinase Inhibitors
}

\author{
Jason S. Gold, MD, Sanne M. van der Zwan, MD, Mithat Gönen, PhD, \\ Robert G. Maki, MD, PhD, Samuel Singer, MD, Murray F. Brennan, MD, \\ Cristina R. Antonescu, MD, and Ronald P. De Matteo, MD
}

Departments of Surgery (JSG, SMV, SS, MFB, RPD), Epidemiology and Biostatistics (MG), Medicine (RGM), and Pathology
(CRA), Memorial Sloan-Kettering Cancer Center, New York, New York, USA

Erratum to: $10.1245 / \mathrm{s} 10434-006-9177-7$

Figure 1 was set incorrectly in the publication of this article. The correct figure appears below:

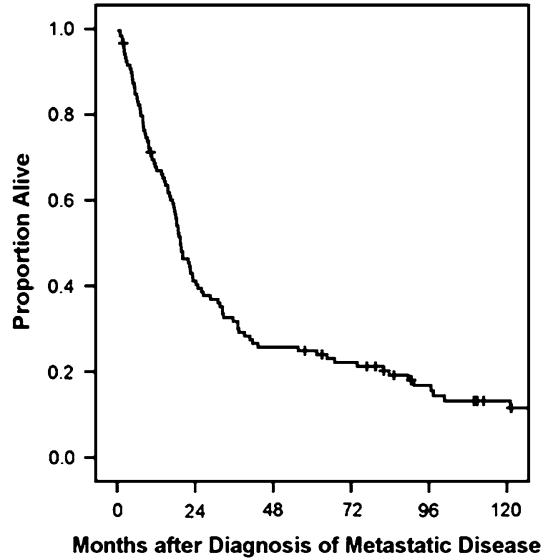

$\begin{array}{lcccc}\begin{array}{l}\text { Number of } \\ \text { patients at risk }\end{array} & 119 & 48 & 28 & 8 \\ \begin{array}{l}\text { Overall } \\ \text { survival (\%) }\end{array} & 100 & 41 & 25 & 13\end{array}$

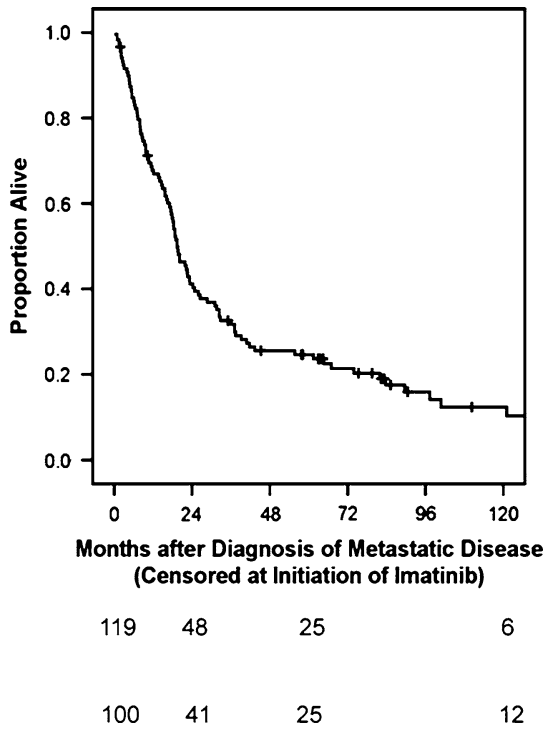

Address correspondence and reprint requests to: Ronald P. De Matteo, MD; Department of Surgery, Memorial Sloan-Kettering Cancer Center, 1275 York Avenue, New York, New York 10021, USA; E-mail: dematter@mskcc.org

Received November 6, 2006; accepted November 6, 2006; published online: July 28, 2007.

Published by Springer Science+Business Media, LLC @ 2007 The Society of Surgical Oncology, Inc. 